\title{
Overexpression of epidermal growth factor receptor as a prognostic factor in colorectal cancer on the basis of the Allred scoring system
}

\author{
Marta Rokita' \\ Rafał Stec' \\ Lubomir Bodnar' \\ Radosław Charkiewicz ${ }^{2}$ \\ Jan Korniluk' \\ Marta Smoter \\ Marzena Cichowicz ${ }^{3}$ \\ Lech Chyczewski ${ }^{4}$ \\ Jacek Nikliński² \\ Wojciech Kozłowski \\ Cezary Szczylik' \\ 'Department of Oncology, Military \\ Institute of Medicine, Central \\ Teaching Hospital, Warsaw, Poland; \\ ${ }^{2}$ Department of Clinical Molecular \\ Biology, Medical University of \\ Bialystok, Bialystok, Poland; \\ ${ }^{3}$ Department of Pathology, Military \\ Institute of the Health Services in \\ Warsaw, Warsaw, Poland; ${ }^{4}$ Department \\ of Clinical Pathology, Medical \\ University of Bialystok, Bialystok, \\ Poland
}

This article was published in the following Dove Press journal:

OncoTargets and Therapy

23 July 2013

Number of times this article has been viewed

Background: Overexpression of epidermal growth factor receptor (EGFR) is found in many types of neoplasms. The aim of the study was to evaluate EGFR expression in colorectal cancer (CRC) specimens and to determine whether EGFR expression correlates with clinicopathological data and overall survival.

Patients and methods: Tissue specimens from 181 consecutive CRC patients treated at the Military Institute of Medicine in 2006-2010 were collected and examined for EGFR expression, by immunohistochemistry staining. The staining intensity and percentage of cells with membranous EGFR expression were scored and then grouped according to the parameters of the Allred Scoring system. Cutoff values were subjected to further statistical analysis. Univariate tests and a multivariate Cox proportional hazards model were used in data analysis.

Results: EGFR was overexpressed in 96 of 181 CRC specimens (53\%). EGFR expression was not correlated with other clinicopathological variables. On univariate analysis, overexpression of EGFR, determined by PS (percentage score) ( $>3$ ) and total score (sum of PS and intensity score) $(>4)$, was associated with poor overall survival. On multivariate analysis, EGFR overexpression (PS > 3) was an independent adverse prognostic factor (hazard ratio [HR] 1.62; 95\% confidence interval [CI]: 1.03-2.53). Elevated carcinoembryonic antigen (CEA) serum concentration before treatment, performance status (Word Health Organization [WHO]-2), and tumor localized in colon and liver metastases were also independent unfavorable prognostic factors.

Conclusion: EGFR overexpression (PS > 3) in a CRC patient population was an independent adverse prognostic factor. Implementation of the Allred Scoring system criteria into clinical practice might facilitate treatment decisions in CRC patients.

Keywords: expression, receptor, prognosis, cancer

\section{Introduction}

Colorectal malignancies remain a leading cause of cancer deaths worldwide in men and women. ${ }^{1}$ Although the overall survival (OS) of patients with colorectal cancer (CRC) has improved over recent decades, prognostic and predictive $\mathrm{CRC}$ biomarkers are still under investigation. Prognostic factors in CRC involve the degree of penetration of the tumor through the intestinal tissues, the nodal involvement status, the presence of distant metastases, bowel obstruction or bowel perforation, and elevated pretreatment carcinoembryonic antigen (CEA) levels. Although epidermal growth factor receptor (EGFR) expression status has proved to be a predictive factor for the administration of anti-EGFR therapies, the data on the prognostic role of EGFR expression in CRC patients are contradictory. ${ }^{2,3}$
Correspondence: Marta Rokita Department of Oncology, Military Medical Institute in Warsaw, Szaserów 128 Street, 0I-I4I Warsaw, Poland Tel +4822 68I 8437 Fax +48226818437 Email martarokita@yahoo.com 
EGFR is a $170-\mathrm{kDa}$ transmembrane tyrosine kinase receptor that belongs to the ErbB family of cell membrane receptors. ${ }^{4}$ All these receptors contain an extracellular ligandbinding region, a single membrane-spanning region, and a cytoplasmic tyrosine kinase-containing domain. ${ }^{5}$ Ligand binding induces dimerization of the receptor with the formation of homodimers and heterodimers, which leads to the activation of tyrosine kinase. The intracellular tyrosine kinase residues then become autophosphorylated, inducing the activation of multiple signal transduction pathways. Two main intracellular pathways activated by EGFR are the mitogenactivated protein kinase (MAPK) pathway and the phosphatidylinositol 3-kinase (PI3K)-protein kinase B (AKT) pathway. These pathways lead to the activation of various transcription factors that then impact cellular responses, such as proliferation, migration, differentiation, and apoptosis. ${ }^{6}$ Transcriptional upregulation, decreased degradation, or gene amplification are recognized to be responsible for EGFR expression. ${ }^{7,8}$

There are data suggesting that EGFR is a strong prognostic factor, as it correlates with increased metastasis, reduced survival, and poor general outcome., ${ }^{4}$ EGFR expression is strongly associated with poor prognosis in head and neck, ovarian, cervical, bladder, and esophageal cancer. ${ }^{10-14}$ It has been shown that EGF and EGFR levels are higher in the malignant zones of CRC specimens than in the surrounding mucosa. ${ }^{15}$ Tumor samples from clinical stage II (T3N0M0) CRC patients has shown EGFR overexpression in neoplastic zones infiltrating the lamina muscularis to the periintestinal adipose tissue, which are considered to be of the most aggressive growth tumor fragments. ${ }^{2,16}$ Evaluation of EGFR expression status is essential in the context of the administration of anti-EGFR therapies, including monoclonal antibodies (mAbs) and small molecule tyrosine kinase inhibitors. There is a need for the appropriate evaluation of EGFR expression, as EGFR status is a key predictive factor for choosing anti-EGFR therapies (eg, cetuximab, panitumumab) in EGFR-positive CRC patients. However, retrospective analyses and Phase II studies have shown that the mAb cetuximab is effective in EGFR-negative CRC patients. ${ }^{17-19}$

In this study, we assessed the prognostic role of EGFR expression status, and its correlation with other clinicopathological features and OS, on the basis of the Allred scoring system, in patients with CRC. ${ }^{20}$

\section{Patients and methods}

The research project was approved by the Ethics Committee of the Military Institute of Medicine, Warsaw, Poland. Prior to a subject's enrollment in the study, the written informed consent form was obtained of all participants.

\section{Patient characteristics}

A total of 181 consecutive patients with CRC and who were treated at the Oncology Department of the Military Institute of the Heath Services, Warsaw between 2006 and 2010 were selected for the study. The inclusion criteria were as follows: histopathological diagnosis of CRC, availability of adequate primary tumor histopathological material, and no prior effect of chemotherapy or radiotherapy on histopathological material. OS was defined as the time interval from the time of diagnosis of metastatic disease to the last contact or time of death. Median follow-up time was 49.43 months. Follow-up was defined as the time interval from the time of the patient's inclusion into the study until the last contact, time of death, or cessation of the study. Patients were followed up during chemotherapy hospitalizations and every 3 months unless the treatment was administered. Patients were censored at the date of the end of follow-up. Clinicopathological data of the 181 CRC patients are reported in Table 1. The median patient age was 65 years (95\% confidence interval [CI], range: 45-78). The majority of primary tumors was located in the sigmoid colon $(\mathrm{n}=70$, $38.7 \%$ ) or colon ( $n=67,37.0 \%)$. The group of patients consisted of $95(52.5 \%)$ women and $86(47.5 \%)$ men. Histological differentiation was poor or unknown in $167(92.3 \%)$ patients. The sites of metastases involved the liver $(\mathrm{n}=116,64.1 \%)$, lungs $(n=36,19.9 \%)$, and other organs $(n=119,65.7 \%)$. Pretreatment CEA levels were elevated above normal range in $80(44.2 \%)$ patients. Most of the patients presented with good performance status (World Health Organization [WHO] 0, $\mathrm{n}=97$ [53.6\%]; WHO 1, n = 74 [40.9\%]). ${ }^{21}$ According to Karnofsky performance status, approximately half of patients $(\mathrm{n}=95,52,5 \%)$ presented with normal performance status and $75(41,4 \%), 10(5,5 \%), 1(0,6 \%)$ of patients were assigned with $90 \%, 80 \%, 70 \%$ Karnofsky score, respectively. Fifty-one patients (28.2\%) received adjuvant chemotherapy, which mainly consisted of a 5 -fluorouracil/leucovorin regimen.

\section{Histology}

Primary tumor tissue specimens of CRC prepared for routine pathological analysis were examined in the study. Samples of surgically removed neoplastic tissues were fixed in $10 \%$ buffered formalin for 24 hours and subsequently converted into paraffin blocks, as per routine procedure. Serial $5 \mu \mathrm{m}$-thick sections of a paraffin block, corresponding to one representative area of the tumor, were then stained with hematoxylin/eosin. Subsequently, tissue samples from 
Table I Patient characteristics $(n=181)$

\begin{tabular}{|c|c|}
\hline Characteristic & \\
\hline \multicolumn{2}{|l|}{ Age, years } \\
\hline Median & 65 \\
\hline $95 \% \mathrm{Cl}$ & $45-78$ \\
\hline \multicolumn{2}{|l|}{ Gender } \\
\hline Female & 95 (52.5\%) \\
\hline Male & $86(47.5 \%)$ \\
\hline \multicolumn{2}{|c|}{ Performance status (World Health Organization) } \\
\hline 0 & 97 (53.6\%) \\
\hline 1 & $74(40.9 \%)$ \\
\hline 2 & $10(5.5 \%)$ \\
\hline \multicolumn{2}{|l|}{ Performance status (Karnofsky) } \\
\hline $70 \%$ & I $(0.6 \%)$ \\
\hline $80 \%$ & $10(5.5 \%)$ \\
\hline $90 \%$ & $75(41.4 \%)$ \\
\hline $100 \%$ & $95(52.5 \%)$ \\
\hline \multicolumn{2}{|l|}{ Histology } \\
\hline Mucinous & $7(3.9 \%)$ \\
\hline Mixed & $52(28.7 \%)$ \\
\hline Cylindocellular & $3(1.7 \%)$ \\
\hline Tubular & $82(45.3 \%)$ \\
\hline Unclassified & 37 (20.4\%) \\
\hline Previous adjuvant chemotherapy & $5 \mathrm{I}(28.2 \%)$ \\
\hline \multicolumn{2}{|c|}{ Pretreatment carcinoembryonic antigen level (ng/mL) } \\
\hline$>5$ & I0I (55.8\%) \\
\hline$\leq 5$ & 80 (44.2\%) \\
\hline \multicolumn{2}{|l|}{ Histological differentiation } \\
\hline Well/moderate & 14 (7.7\%) \\
\hline Poorly/unknown & $167(92.3 \%)$ \\
\hline \multicolumn{2}{|l|}{ Lymph node status } \\
\hline No & 27 (I4.9\%) \\
\hline $\mathrm{NI}$ & $40(22.1 \%)$ \\
\hline $\mathrm{N} 2 \mathrm{a}$ & 27 (14.9\%) \\
\hline $\mathrm{N} 2 \mathrm{~b}$ & $25(13.8 \%)$ \\
\hline $\mathrm{Nx}$ & $62(34.3 \%)$ \\
\hline \multicolumn{2}{|l|}{ Invasive extent } \\
\hline Tx & 14 (7.7\%) \\
\hline $\mathrm{T} 2$ & $9(5.0 \%)$ \\
\hline T3 & $139(76.8 \%)$ \\
\hline T4 & $19(10.5 \%)$ \\
\hline \multicolumn{2}{|l|}{ Primary tumor site } \\
\hline Colon & 67 (37.0\%) \\
\hline Sigmoid & $70(38.7 \%)$ \\
\hline Rectum & $44(24.3 \%)$ \\
\hline \multicolumn{2}{|l|}{ Sites of metastases } \\
\hline Liver & $116(64.1 \%)$ \\
\hline Lung & $36(19.9 \%)$ \\
\hline Other & $119(65.7 \%)$ \\
\hline \multicolumn{2}{|l|}{ Number of organs involved } \\
\hline 1 & $69(38.1 \%)$ \\
\hline$\geq 2$ & $112(61.9 \%)$ \\
\hline
\end{tabular}

Abbreviation: $\mathrm{Cl}$, confidence interval.

at least three serial sections were macrodissected to ensure that specimens contained at least $80 \%$ tumor cells. The slides were reviewed by two independent pathologists, to confirm the diagnosis and evaluate EGFR status. The pathologists were blinded to each other and to the clinicopathological data. In cases of discrepancy between the investigators, the definitive diagnosis was achieved by consensus.

\section{Immunohistochemical analysis}

The paraffin-embedded tissues fixed in $10 \%(\mathrm{v} / \mathrm{v})$ neutral buffered formalin were cut at $5 \mu \mathrm{m}$ thickness. Immunostaining of sections was performed using the EGFR pharmDx ${ }^{\text {TM }}$ kit (Dako, Glostrup, Denmark), which includes EGFR pharmDx monoclonal mouse antibody (clone 2-18C9), proteinase $\mathrm{K}$, peroxidase block, mouse immunoglobulin (Ig) G1 negative control reagent, labeled polymer human serum protein (HRP), 3,3'-diaminobenzine (DAB) + substrate buffer, liquid DAB + chromogen, DakoCytomation wash solution $10 \times$, and EGFR pharmDx control slides. The immunohistochemical technique was performed according to the instructions supplied by the manufacturer. The controls used for the validation of EGFR assay were included in the EGFR pharmDx kit: negative control reagent, a positive control (human cell line HT29, representing moderate [2+] EGFR expression), and a negative control (human cell line CAMA-1, representing the absence of EGFR expression) cell preparation.

\section{Evaluation of EGFR expression status}

EGFR expression was defined as membranous and/or cytoplasmic immunohistological brown staining of tumor cells with various intensity. Positivity for EGFR expression was taken as any membrane staining above background level, whether this was complete or incomplete circumferential staining. The primary tumor was considered positive when $\geq 1 \%$ of the neoplastic cells had membranous staining. Specific membrane immunostaining in less than $1 \%$ of tumor cells was defined as EGFR-negative. The Allred scoring system for assessing the expression of steroid hormone receptors in breast cancer served as a pattern for our assessment of EGFR expression. An immunohistochemical interpretation was performed on the histopathological material, from which we obtained a proportion score (PS) and an intensity score (IS). The PS score was the percentage ratio of positive EGFR-stained tumor cells to the total number of cells, classified as: PS0 (0\%), PS1 $(>0 \%-1 \%)$, PS2 $(\geq 1 \%-10 \%)$, PS3 $(>10 \%-33 \%)$, PS4 $(>33 \%-66 \%)$, and PS5 (>66\%-100\%). The IS score measured staining intensity by visual assessment and was scored as: 0 (negative), $1+$ (weak), 2+ (moderate), or 3+ (strong). The total score (TS) was calculated as the sum of the PS and IS and ranged from 0 to 8 . PS $\leq 3$ and TS $\leq 4$ were defined as low EGFR expression, whereas PS $>3$ and TS $>4$ were defined as 
high EGFR expression. The intensity of EGFR staining was considered to be low for IS $\leq 1$ and high for IS $>1$.

\section{Statistical analysis}

The Chi-square test was used to investigate the association between variables in the two treatment groups with respect to baseline characteristics. Median and life tables were computed using the product limit estimate by the Kaplan-Meier method, and the logrank test was employed to assess the statistical significance, $P$-values less than 0.05 were considered to indicate statistical significance. Kaplan-Meier curves served to compare the following groups of patients: PS $\leq 3$ and $\mathrm{PS}>3$, IS $\leq 1$ and $\mathrm{IS}>1, \mathrm{TS} \leq 4$ and TS $>4$. Univariate and multivariate proportional hazard models (Cox) were fitted to the data to determine the importance of recognized explanatory variables. Factors that were significant in univariate analysis and factors that showed a trend towards significance were included in the multivariate model evaluating the factors potentially influencing OS (ie, sites of metastases, primary tumor localization, pretreatment CEA level, PS score, and performance status). A Cox proportional hazard regression using the forward stepwise method was performed in the multivariate analyses of OS. Statistical calculations were performed using the STATISTICA 7.0 for Windows software (StatSoft Inc, Tulsa, OK, USA).

\section{Results EGFR expression analysis}

EGFR expression was confirmed in $96(53 \%)$ of 181 colorectal neoplasms. The PS, IS, TS assessed according to a modified Allred scoring system, adjusted for assessment of membranous EGFR expression, are shown in Table 2. The majority of EGFR-positive tumor specimens were scored as

Table 2 Epidermal growth factor receptor expression in colorectal cancer patients $(n=181)$

\begin{tabular}{llllll}
\hline $\begin{array}{l}\text { Proportion } \\
\text { score (PS) }\end{array}$ & N (\%) & $\begin{array}{l}\text { Intensity } \\
\text { score (IS) }\end{array}$ & $\mathbf{N}(\%)$ & $\begin{array}{l}\text { Total } \\
\text { score (TS) }\end{array}$ & N (\%) \\
\hline 0 & $85(47)$ & 0 & $85(47)$ & 0 & $85(47)$ \\
1 & $1(0.6)$ & 1 & $29(16)$ & 2 & $1(0.6)$ \\
2 & $40(22.1)$ & 2 & $58(32)$ & 3 & $15(8,2)$ \\
3 & $18(9.9)$ & 3 & $9(5)$ & 4 & $29(16)$ \\
4 & $18(9.9)$ & & & 5 & $17(9.4)$ \\
5 & $19(10.5)$ & & 6 & $17(9.4)$ \\
& & & & 7 & $14(7.7)$ \\
& & & & 8 & $3(1.7)$ \\
\hline
\end{tabular}

Notes: PS was classified as: PSO (0\%), PSI ( $>0 \%-1 \%)$, PS2 ( $\geq 1 \%-10 \%)$, PS3 $(>10 \%-33 \%)$, PS4 $(>33 \%-66 \%)$, or PS5 $(>66 \%-100 \%)$. IS was classified as: 0 (negative), I+ (weak), $2+$ (moderate), or 3+ (strong). TS = PS + IS.

Abbrevations: PS, proportion score; IS, intensity score; TS, total score.
Table 3 Clinicopathological features in metastatic colorectal cancer patients according to EGFR expression

\begin{tabular}{|c|c|c|c|}
\hline Parameter & $\begin{array}{l}\text { High expression } \\
\text { of EGFR } \\
(\mathrm{TS}>4)\end{array}$ & $\begin{array}{l}\text { Low expression } \\
\text { of EGFR } \\
(T S \leq 4)\end{array}$ & P-value \\
\hline \multicolumn{4}{|l|}{ Age (years) } \\
\hline$\leq 75$ & 45 & 114 & 0.6326 \\
\hline$>75$ & 7 & 14 & \\
\hline \multicolumn{4}{|l|}{ Gender } \\
\hline Male & 25 & 61 & 0.9233 \\
\hline Female & 27 & 68 & \\
\hline \multicolumn{4}{|c|}{ Histologic differentiation } \\
\hline Well/moderate & 12 & 18 & 0.1353 \\
\hline Poorly/unknown & 40 & III & \\
\hline \multicolumn{4}{|l|}{ Primary tumor } \\
\hline Colon & 22 & 45 & 0.3493 \\
\hline Sigmoid/rectum & 30 & 84 & \\
\hline \multicolumn{4}{|c|}{ Performance status (World Health Organization) } \\
\hline $0-1$ & 46 & 125 & $0.0589 *$ \\
\hline 2 & 6 & 4 & \\
\hline \multicolumn{4}{|c|}{ Performance status (Karnofsky) } \\
\hline$\leq 80$ & 6 & 5 & $0.1077^{*}$ \\
\hline$>80$ & 46 & 124 & \\
\hline \multicolumn{4}{|l|}{ Invasive extent } \\
\hline$T x-2$ & 5 & 18 & $0.5848^{*}$ \\
\hline T3-4 & 47 & 111 & \\
\hline \multicolumn{4}{|l|}{ Nodal status } \\
\hline Negative & 8 & 19 & 0.9057 \\
\hline Positive & 44 & 110 & \\
\hline \multicolumn{4}{|l|}{ Sites of metastases } \\
\hline Liver & 33 & 83 & 0.9111 \\
\hline Other & 19 & 46 & \\
\hline \multicolumn{4}{|c|}{ Number of organs involved } \\
\hline I & 23 & 46 & 0.2826 \\
\hline$\geq 2$ & 29 & 83 & \\
\hline \multicolumn{4}{|c|}{ Pretreatment carcinoembryonic antigen level $(\mathrm{ng} / \mathrm{mL})$} \\
\hline$>5$ & 25 & 55 & 0.5048 \\
\hline$\leq 5$ & 27 & 74 & \\
\hline
\end{tabular}

Note: ${ }^{* P}$-values calculated by the Chi-square test with Yates correction. Abbreviations: EGFR, epidermal growth factor receptor; TS, total score.

PS2 (40 [22,1\%]) and IS2 (58 [32\%]). A predominant value of TS4 was found in 29 (16\%) of EGFR-positive patients.

There was no correlation between EGFR expression and other clinicopathological data (Table 3).

\section{EGFR as a prognostic factor} in univariate analysis

Univariate analysis of association between clinicopathological variables and OS revealed age, the primary tumor site, WHO and Karnofsky performance status scores, metastatic sites, the pretreatment CEA level, PS, and TS to be statistically significant. The full characteristics are shown in Tables 4 and 5. The median OS was better in the $144(79,6 \%)$ patients who scored PS $\leq 3$ compared with the $37(20,4 \%)$ 
Table 4 Univariate analysis of overall survival (logrank test)

\begin{tabular}{|c|c|c|c|}
\hline Covariate & $\mathbf{N}(\%)$ & $\begin{array}{l}\text { Median overall } \\
\text { survival (months) }\end{array}$ & $P$-value \\
\hline \multicolumn{4}{|l|}{ Age (years) } \\
\hline$\leq 75$ & $160(88.4 \%)$ & 41.3 & $0.0099 *$ \\
\hline$>75$ & $21(11.6 \%)$ & 17.0 & \\
\hline \multicolumn{4}{|l|}{ Gender } \\
\hline Male & $86(47.5 \%)$ & 40.7 & 0.5338 \\
\hline Female & 95 (52.5\%) & 31.7 & \\
\hline \multicolumn{4}{|c|}{ Histological differentiation } \\
\hline Well/moderate & I5I (83.4\%) & 42.5 & 0.5951 \\
\hline Poorly/unknown & $30(16.6 \%)$ & 25.3 & \\
\hline \multicolumn{4}{|l|}{ Primary tumor } \\
\hline Colon & $67(37.0 \%)$ & 24.5 & $0.0006^{*}$ \\
\hline Sigmoid/rectum & II 4 (63.0\%) & 45.7 & \\
\hline \multicolumn{4}{|c|}{ Performance status (World Health Organization) } \\
\hline $0-1$ & I7I (94.5\%) & 41.0 & $0.0016^{*}$ \\
\hline 2 & $10(5.5 \%)$ & 13.0 & \\
\hline \multicolumn{4}{|c|}{ Performance status (Karnofsky) } \\
\hline$\leq 80$ & $11(6.1 \%)$ & 13.5 & $0.0048 *$ \\
\hline$>80$ & $170(93.9 \%)$ & 40.0 & \\
\hline \multicolumn{4}{|l|}{ Invasive extent } \\
\hline Tx-2 & $23(12.7 \%)$ & 23.8 & 0.4304 \\
\hline T3-4 & I $58(87.3 \%)$ & 39.4 & \\
\hline \multicolumn{4}{|l|}{ Nodal status } \\
\hline Negative & 27 (I4.9\%) & 33.3 & 0.9566 \\
\hline Positive & $154(85.1 \%)$ & 38.5 & \\
\hline \multicolumn{4}{|l|}{ Sites of metastases } \\
\hline Liver & $116(64.1 \%)$ & 30.2 & $0.0274 *$ \\
\hline Other & $65(35.9 \%)$ & 47.0 & \\
\hline \multicolumn{4}{|c|}{ Number of organs involved } \\
\hline I & $69(38.1 \%)$ & 32.8 & 0.2686 \\
\hline$\geq 2$ & $112(61.9 \%)$ & 39.4 & \\
\hline \multicolumn{4}{|c|}{ Pretreatment carcinoembryonic antigen level (ng/mL) } \\
\hline$\leq 5$ & $101(55.8 \%)$ & 24.5 & $<0.0001 *$ \\
\hline$>5$ & $80(44.2 \%)$ & 55.8 & \\
\hline \multicolumn{4}{|l|}{ Proportion score } \\
\hline$\leq 3$ & I 44 (79.6\%) & 40.4 & $0.0075^{*}$ \\
\hline$>3$ & 37 (20.4\%) & 26.4 & \\
\hline \multicolumn{4}{|l|}{ Intensity score } \\
\hline$\leq 1$ & 114 (63.0\%) & 40.5 & 0.8227 \\
\hline$>1$ & 67 (37.0\%) & 34.4 & \\
\hline \multicolumn{4}{|l|}{ Total score } \\
\hline$\leq 4$ & I 30 (7|,8\%) & 39.7 & $0.0335^{*}$ \\
\hline$>4$ & $5 \mathrm{I}(28,2 \%)$ & 27.2 & \\
\hline
\end{tabular}

Note: *Statistically significant $(P<0.05)$.

patients who scored PS $>3$ (40.4 months versus 26.4 months, respectively) $(P=0.0075)$ (Figure 1). The IS parameter had no prognostic value $(P=0.8227)$ (Figure 2$)$. The $130(71,8 \%)$ patients who scored TS $\leq 4$ showed better median OS compared with the $51(28,2 \%)$ patients who scored TS $>4$ (39.7 months versus 27.2 months, respectively) $(P=0.0335)$ (Figure 3). The EGFR expression status, as determined by a cutoff at PS $>3$, was independently correlated with poor prognosis.

\section{EGFR as a prognostic factor}

\section{in multivariate analysis}

Multivariate analysis of the clinicopathological data found metastatic sites, primary tumor site, WHO performance status, pretreatment CEA level and PS to be statistically significant (Table 5). High EGFR expression determined by PS $>3$ was independently correlated with poor OS (HR 1.62; $95 \%$ CI: $1.03-2.53, P=0.0359$ ).

\section{Discussion}

According to the literature, the prognostic role of EGFR expression status in human neoplasms remain controversial. ${ }^{2,3}$ We therefore performed a prospective study to evaluate EGFR expression as a prognostic factor and to assess the correlation between EGFR expression status and other clinicopathological data.

Our study revealed EGFR-positivity in 96 (53\%) tumor specimens. These results are consistent with the results of the studies reporting EGFR expression ranging from 25\% to $82 \% .^{3,22-26}$ The wide range of EGFR expression in CRC may be related to the methodology used to detect EGFR expression. ${ }^{5}$

Although parameters such as PS, IS, and TS were used for evaluating EGFR expression status in recent studies, the detailed criteria we used to define cutoffs of individual parameters were different from those used by others. ${ }^{2,4}$ Spano et $\mathrm{al}^{2}$ used only the TS parameter for statistical analysis, which failed to demonstrate EGFR status as an independent prognostic variable. Further, in that study, the PS and IS parameters were not analyzed separately, and the TS parameter was achieved by multiplying the PS and IS, whereas, in our study, the TS was obtained by adding the Allred scored PS and IS parameters. Our study included more detailed data related to the EGFR status, and this could explain the correlation of EGFR status and poor survival we found. The available data in the literature concerning cutoffs for positive staining for EGFR expression is lacking or incoherent. ${ }^{27-30} \mathrm{~A}$ cutoff value of $1 \%$ of the stained cells served to determine positive or negative EGFR status, as in other studies. ${ }^{2,31}$

We found high EGFR expression to be an independent factor of poor prognosis in CRC. However, only the PS parameter (PS > 3) proved to be an independent prognostic biomarker, both in univariate and multivariate analysis. We failed to prove IS as prognostic factor in univariate and multivariate analysis. This is inconsistent with other studies, which demonstrate IS to be prognostic. ${ }^{3,4}$ Rego et $\mathrm{al}^{4}$ found that increased EGFR IS was associated with significantly 
Table 5 Univariate and multivariate analysis of overall survival

\begin{tabular}{|c|c|c|c|c|c|c|c|c|}
\hline \multirow[t]{2}{*}{ Covariate } & \multicolumn{4}{|c|}{ Univariate analysis } & \multicolumn{4}{|c|}{ Multivariate analysis } \\
\hline & HR & $-95 \% \mathrm{Cl}$ & $+95 \% \mathrm{Cl}$ & P-value & HR & $-95 \% \mathrm{Cl}$ & $+95 \% \mathrm{Cl}$ & P-value \\
\hline \multicolumn{9}{|l|}{ Sites of metastases } \\
\hline Liver vs other & 1.57 & 1.03 & 2.40 & 0.0358 & 2.13 & 1.33 & 3.40 & 0.0017 \\
\hline \multicolumn{9}{|l|}{ Primary tumor } \\
\hline Colon vs sigmoid/rectum & 2.05 & 1.38 & 3.06 & 0.0004 & 2.19 & 1.45 & 3.32 & 0.0002 \\
\hline \multicolumn{9}{|c|}{ Performance status (World Health Organization) } \\
\hline 2 vs $0-1$ & 3.76 & 1.93 & 7.33 & $<0.0001$ & 6.25 & 2.97 & 13.16 & $<0.0001$ \\
\hline \multicolumn{9}{|c|}{ Pretreatment carcinoembryonic level (ng/mL) } \\
\hline$>5$ vs $\leq 5$ & 2.18 & 1.65 & 2.88 & $<0.0001$ & 2.04 & 1.52 & 2.73 & $<0.0001$ \\
\hline \multicolumn{9}{|l|}{ Proportion score } \\
\hline$>3$ vs $\leq 3$ & 1.83 & 1.19 & 2.84 & 0.0063 & 1.62 & 1.03 & 2.53 & 0.0359 \\
\hline \multicolumn{9}{|l|}{ Age (years) } \\
\hline$>75$ vs $\leq 75$ & 2.23 & 1.30 & 3.82 & 0.0035 & - & - & - & NS \\
\hline \multicolumn{9}{|l|}{ Performance status (Karnofsky) } \\
\hline$\leq 80$ vs $>80$ & 2.70 & 1.44 & 5.07 & 0.0019 & - & - & - & NS \\
\hline \multicolumn{9}{|l|}{ Total score } \\
\hline$>4$ vs $\leq 4$ & 1.53 & 1.02 & 2.30 & 0.0382 & - & - & - & NS \\
\hline
\end{tabular}

Abbreviations: $\mathrm{Cl}$, confidence interval; $\mathrm{HR}$, hazard ratio; NS, not significant.

shorter OS in univariate analysis. Patients with tumors that showed strong staining (IS3) had reduced OS of borderline statistical significance $(P=0.047) .{ }^{4}$ However, the study of Rego et al had greater power, and this could explain a weak association of IS with OS observed in their study $(\mathrm{HR}=1.2) .{ }^{4}$ There are a few hypotheses to explain the lack of correlation between IS parameter and OS. Our patients consisted of small group of patients scored IS3 $(n=9,5 \%)$, which may have had a significant impact on the statistical analysis. A wide range in incidence (17\% to $55 \%$ ) of patients scoring IS3 is described in the literature. ${ }^{2,10}$ Moreover, IS is scored by the number of EGFR receptors located on the cell membrane. The number of cell enzymes responsible for the specific signal transduction pathway is limited. There is a set point of enzyme saturation, above which the membrane EGFR receptor number does not influence

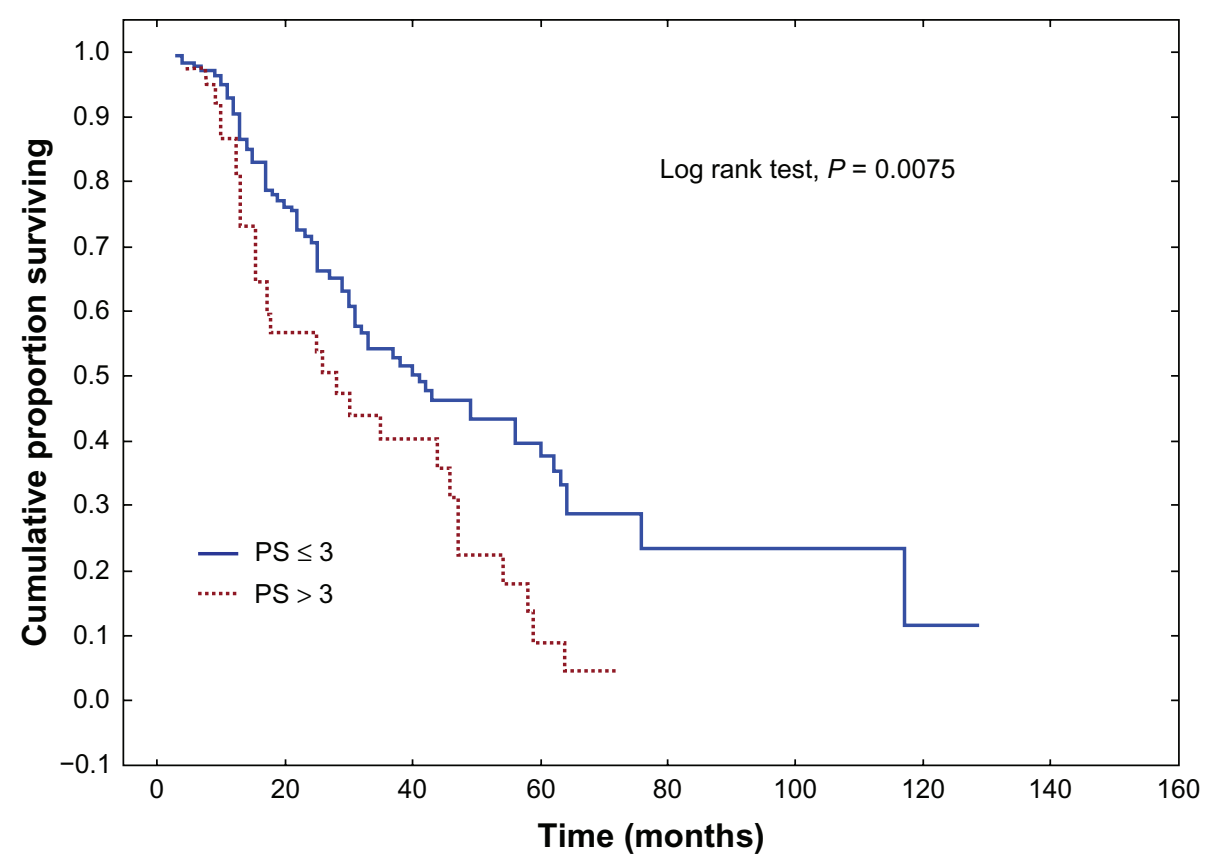

Figure I Overall survival (Kaplan-Meier) for colorectal cancer patients, stratified by expression of epidermal growth factor receptor, according to the estimated proportion of positive tumor cells on the entire slide in the Allred scoring system.

Note: $P$-value was calculated using the logrank test.

Abbreviation: PS, proportion score. 


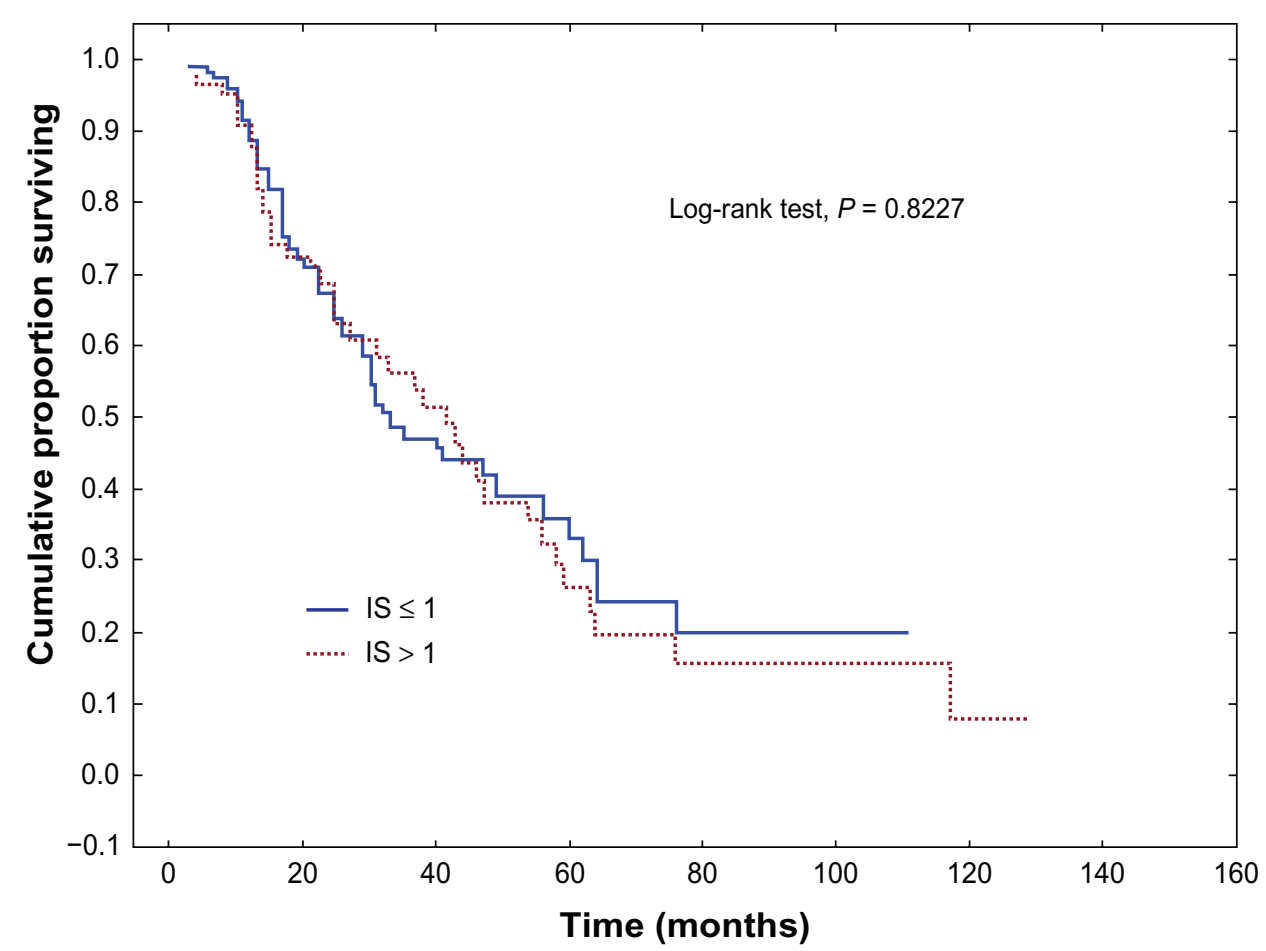

Figure 2 Overall survival (Kaplan-Meier) for colorectal cancer patients, stratified by expression of epidermal growth factor receptor, according to the estimated average staining intensity of positive tumor cells in the Allred scoring system.

Note: $P$-value was calculated using the logrank test.

Abbreviation: IS, intensity score.

the cellular response to EGFR stimulation. Furthermore, discrepancies in the technological methods should not be excluded, for eg, inappropriately titrated mAbs or different $\mathrm{mAb}$ affinity affects intensity staining. The subjective opinion of the pathologist assessing the IS should also be considered. There are also data suggesting a poor prognosis in patients with an increased sarcomatoid component, which is generally associated with more aggressive tumor growth in renal carcinomas with the mixed histopathology of clear cell and sarcomatoid component. ${ }^{32}$ Therefore, the percentage of EGFR-positive tumor cells may be supposed to have been the malignant tumor component associated with more invasive tumor regions and may have influenced OS regardless of the IS. Nevertheless, PS $>3$, defined as greater than $33 \%$ of stained cells in the tumor, proved to be an independent prognostic factor in our study. These results were consistent with the results of Mayer et $\mathrm{al}^{33}$ who found a cutoff of more than $50 \%$ of EGFR-positive tumor cells to be a negative prognostic factor in CRC patients $(P<0.01){ }^{33}$ Goldstein and $\mathrm{Armin}^{3}$ found an increasing incidence of IS2 and IS3 - or IS3 only - reactivity in the deep tumor region to have the strongest correlation with poor survival $(P=$ 0.0252). The cutoff value for PS was undetermined in their study, though. ${ }^{3} \mathrm{TS}$ proved to be prognostic in the univariate analysis, and this was probably influenced by PS, which was found to be an independent prognostic factor in both uni- and multivariate analysis.

We found no correlation between EGFR expression and other clinicopathological data, which is partly consistent with other studies. The results of our study are consistent with the majority of published studies, which show no association between EGFR expression and the site of the primary tumor. ${ }^{2,3,32}$ Our study found no correlation between EGFR expression and tumor differentiation grade, patient gender, or patient age. This is consistent with other studies. ${ }^{2,3,22,35-38}$ However, there are studies showing an association between EGFR expression and tumor differentiation grade. ${ }^{24,35,39} \mathrm{~A}$ possible explanation may be that we classified tumors of unknown histologic differentiation together with poorly differentiated tumors. We found no relationship between tumor extension and EGFR expression. However, there are studies that report such correlations. ${ }^{2,3}$ Spano et $\mathrm{al}^{2}$ found a correlation between TNM tumor stage T3 and high EGFR expression $(P=0.006)$. Goldstein and $\mathrm{Armin}^{3}$ found higher EGFR expression in the deepest regions of the tumors. However, the study group consisted of patients with TNM staging T3N1-2M1. This could be because we categorized tumors staged $\mathrm{Tx}$ together with tumors staged T2, and they 


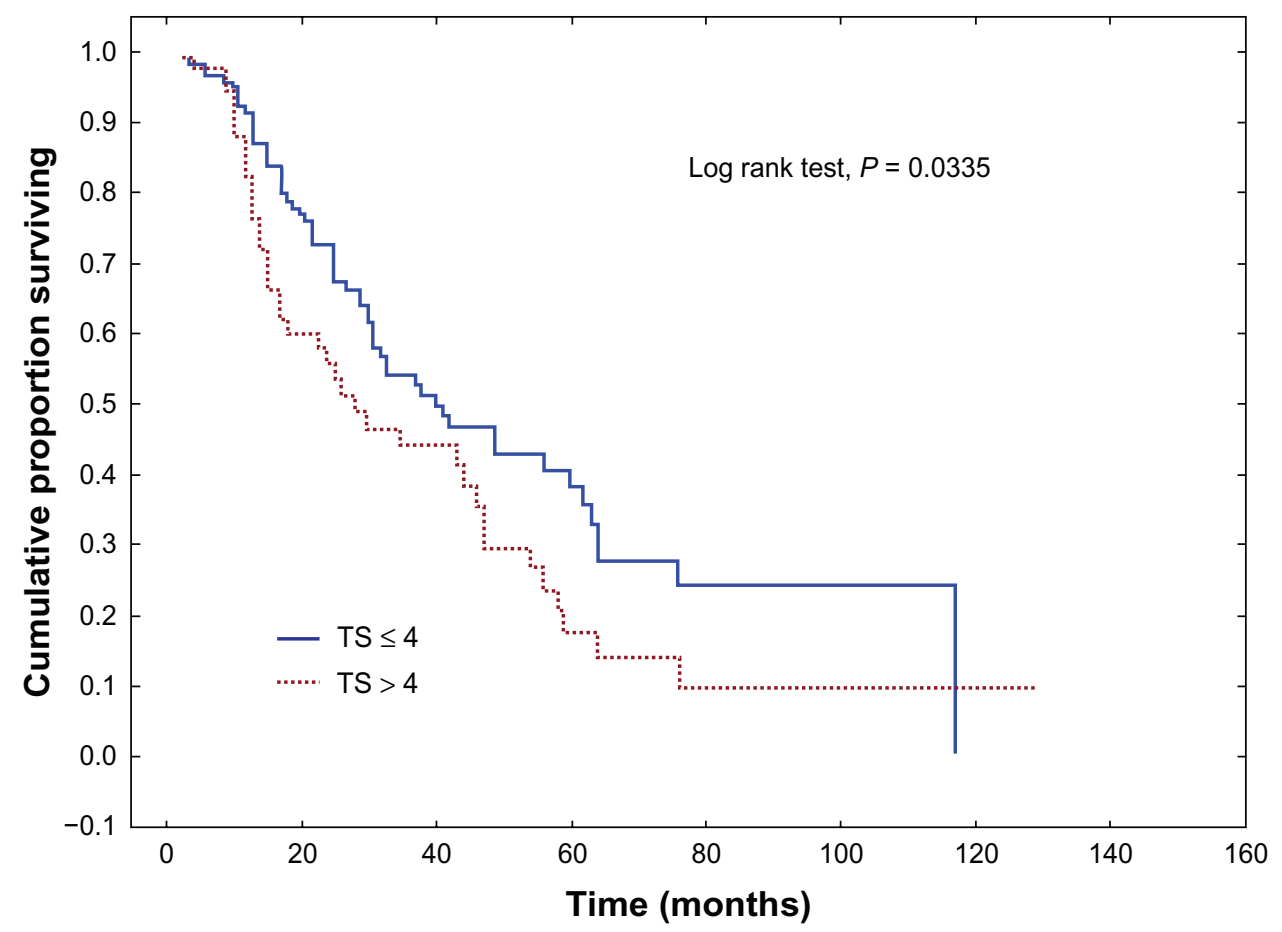

Figure 3 Overall survival (Kaplan-Meier) for colorectal cancer patients, stratified by expression of epidermal growth factor receptor, according to the total score in the Allred scoring system.

Note: $P$-value was calculated using the logrank test.

Abbreviation: TS, total score.

were therefore assessed as being less invasive. Nodal status was not correlated with EGFR expression in our study. The data concerning nodal status and EGFR expression are controversial. There are studies proving such correlation,, 38 whereas others do not., ${ }^{2,424}$ In our study, the unknown nodal status of $\mathrm{Nx}$ was considered as a positive nodal status, which may have had an impact on the results. Moreover, the correlation of sites of metastases and the number of organs involved with EGFR expression showed no statistical significance in our study. No association between pretreatment CEA level and EGFR expression was also revealed, which is generally consistent with the results of Spano et al. ${ }^{2}$

Defective methodology (for eg, in the immunohistochemical staining, specimen fixation, and storage or in the interval between specimen fixation and immunohistochemical examination) might explain the incompatibility between the EGFR expression status and the immunohistochemical staining. ${ }^{18,40,41}$ Our experience with HER2 expression in breast cancer, has shown that immunohistochemistry is highly dependent on the antibody clone that is used, the selection of scoring methods, and the selection of cutoff values. ${ }^{5}$ Differences in EGFR expression between metastatic tumor and primary tumor specimens should also be considered. At least one analysis has shown EGFR expression in metastatic tumors with no EGFR expression in the primary tumor. ${ }^{18}$ Another study showed no evidence of EGFR expression in metastatic tumors despite EGFR expression-positive primary tumors. ${ }^{42}$ The site of tumor sampling influences the results of EGFR staining, as intense EGFR expression is related to the most invasive and deeply located tumor tissues. ${ }^{3}$ All these factors contribute to a wide range of EGFR expression, ranging from $25 \%$ to $82 \%$ of tumor specimens. ${ }^{3,22-26}$

\section{Conclusion}

In the light of our results, further investigations into standardizing EGFR detection techniques are recommended. This is because EGFR expression is correlated with more aggressive neoplastic disease and could be used as an indication for the introduction of anticancer therapies in the early stages of CRC or as adjuvant chemotherapy. Therefore, the implementation of the Allred scoring system into the assessment of EGFR expression status seems to be an interesting option.

\section{Acknowledgments}

This work was supported by a grant from the Military Institute of the Health Services, Warsaw, Poland, Grant No: WIM$50 / 2008$ and WIM-45/2009. These foundations had no role in 
study design, data collection, analysis or writing of the paper and decision to submit the paper for publication.

\section{Disclosure}

The authors report no conflict of interest in this study.

\section{References}

1. Hawk ET, Linburg PJ, Viner JL. Epidemiology and prevention of colorectal cancer. Surg Clin North Am. 2002;82(5):905-941.

2. Spano JP, Lagorce C, Atlan D, et al. Impact of EGFR expression on colorectal cancer patient prognosis and survival. Ann Oncol. 2005;16(1): 102-108.

3. Goldstein NS, Armin M. Epidermal growth factor receptor immunohistochemical reactivity in patients with American Joint Committee on Cancer Stage IV colon adenocarcinoma: implications for a standardized scoring system. Cancer. 2001;92(5):1331-1346.

4. Rego RL, Foster NR, Smyrk TC, et al. Prognostic effect of activated EGFR expression in human colon carcinomas: comparison with EGFR status. Br J Cancer. 2010;102(1):165-172.

5. Krasinskas AM. EGFR Signaling in colorectal carcinoma. Patholog Res Int. 2011;2011:932932.

6. Citri A, Yarden Y. EGF-ERBB signaling: towards the systems level. Nat Rev Mol Cell Biol. 2006;7(7):505-516.

7. Komuta K, Koji T, Izumi S, et al. Expression of epidermal growth factor receptor messenger RNA in human colorectal carcinomas assessed by nonradioactive in-situ hybridization. Eur J Surg Oncol. 1995;21(3):269-275.

8. Shia J, Klimstra DS, Li AR, et al. Epidermal growth factor receptor expression and gene amplification in colorectal carcinoma: an immunohistochemical and chromogenic in situ hybridization study. Mod Pathol. 2005;18(10):1350-1356.

9. Pericay C, Santos-Vivas C, Pous-Saltor E, et al. Epidermal growth factor receptor (EGFR) as a prognostic factor over 10 years in non-metastatic colon carcinoma (NMCC). J Clin Oncol (ASCO Meeting Abstracts). 2007;25(Suppl 18):S21062. Abstract.

10. Maurizi M, Almadori G, Ferrandina G, et al. Prognostic significance of epidermal growth factor receptor in laryngeal squamous cell carcinoma. Br J Cancer. 1996;74(8):1253-1257.

11. Fischer-Colbrie J, Witt A, Heinzl H, et al. EGFR and steroid receptors in ovarian carcinoma: comparison with prognostic parameters and outcome of patients. Anticancer Res. 1997;17(1B):613-619.

12. Kersemaekers AM, Fleuren GJ, Kenter GG, et al. Oncogene alterations in carcinomas of the uterine cervix: overexpression of the epidermal growth factor receptor is associated with poor prognosis. Clin Cancer Res. 1999;5(3):577-586.

13. Mellon K, Wright C, Kelly P, Horne CH, Neal DE. Long-term outcome related to epidermal growth factor receptor status in bladder cancer J Urol. 1995;153(3 Pt 2):919-925.

14. Inada S, Koto T, Futami K, Arima S, Iwashita A. Evaluation of malignancy and the prognosis of esophageal cancer based on an immunohistochemical study (p53, E-cadherin, epidermal growth factor receptor). Surg Today. 1999;29(6):493-503.

15. Messa C, Russo F, Caruso MG, Di Leo A. EGF, TGF-alpha, and EGFR-R in human colorectal adenocarcinoma. Acta Oncol. 1998;37(3): 285-289.

16. Edge SB, Byrd DR, Compton CC, FritzAG, Greene FL, TrottiA, eds. AJCC Cancer Staging Handbook. 7th ed. New York: Springer-Verlag;2010.

17. Lenz HJ, Van Cutsem E, Khambata-Ford S, et al. Multicenter phase II and transational study of cetuximab in metastatic colorectal carcinoma refractory to irinotecan, oxaliplatin and fluoropirymidines. J Clin Oncol. 2006;24(30):4914-4921.

18. Chung KY, Shia J, Kemeny NE, et al. Cetuximab shows activity in colorectal cancer patients with tremors that do not express the epidermal growth factor receptor by immunostaining. J Clin Oncol. 2005;23(9):1803-1810.
19. Hebbar M, Wacrenier A, Deesauw C, et al. Lack of usefulness of epidermal growth factor receptor expression determination for cetuximab therapy in patients with colorectal cancer. Anticancer Drugs. 2006;17(7):855-857.

20. Allred DC, Harvey JM, Berardo M, Clark GM. Prognostic and predictive factors in breast cancer by immunohistochemical analysis. Mod Pathol. 1998;11(2):155-168.

21. Oken MM, Creech RH, Tormey DC, et al. Toxicity And Response Criteria OfThe Eastern Cooperative Oncology Group. Am J Clin Oncol. 1982;5(6):649-655.

22. Yarden Y, Sliwkowski MX. Untangling the ErbB signalling network. Nat Rev Mol Cell Biol. 2001;2(2):127-137.

23. Radinsky R, Risin S, Fan D, et al. Level and function of epidermal growth factor receptor predict the metastatic potential of human colon carcinoma cells. Clin Cancer Res. 1995;1(1):19-31.

24. McKay JA, Murray LJ, Curran S, et al. Evaluation of the epidermal growth factor receptor (EGFR) in colorectal tumours and lymph node metastases. Eur J Cancer. 2002;38(17):2258-2264.

25. Wan CW, McKnight MK, Brattain DE, Brattain MG, Yeoman LC. Different epidermal growth factor growth responses and receptor levels in human colon carcinoma cell lines. Cancer Lett. 1988;43(1-2): 139-143.

26. Cunningham D, Humblet Y, Siena S, et al. Cetuximab monotherapy and cetuximab plus irinotecan in irinotecan-refractory metastatic colorectal cancer. N Engl J Med. 2004;351(4):337-345.

27. Garcia I, Vizoso F, Martin A, et al. Clinical significance of the epidermal growth factor receptor and HER2 receptor in resectable gastric cancer. Ann Surg Oncol. 2003;10(3):234-241.

28. Kopp R, Rothbauer E, Ruge M, et al. Clinical implications of the EGF receptor/ligand system for tumor progression and survival in gastrointestinal carcinomas: evidence for new therapeutic options. Recent Results Cancer Res. 2003;162:115-132.

29. Gamboa-DominguezA, Dominguez-Fonseca C, Quintanilla-Martinez L, et al. Epidermal growth factor expression correlates with poor survival in gastric adenocarcinoma from Mexican patients: a multivariate analysis using a standardized immunohistochemical detection system. Mod Pathol. 2004;17(5):579-587.

30. Ito R, Nakayama H, Yoshida K, Matsumura S, Oda N, Yasui W. Expression of $\mathrm{Cbl}$ linking with the epidermal growth factor receptor system is associated with tumor progression and poor prognosis of human gastric carcinoma. Virchows Asch. 2004;444(4): 324-331.

31. Galizia G, Lieto E, Orditura M, et al. Epidermal growth factor receptor (EGFR) expression is associated with worse prognosis in gastric cancer patients undergoing curative surgery. World J Surg. 2007;31(7):1458-1468.

32. Golshayan AR, George S, Heng DY, et al. Metastatic sarcomatoid renal cell carcinoma treated with vascular endothelial growth factor-targeted therapy. J Clin Oncol. 2009;27(2):235-241.

33. Mayer A, Takimoto M, Fritz E, Schellander G, Kofler K, Ludwig H. The prognostic significance of proliferating cell nuclear antigen, epidermal growth factor receptor, and mdr gene expression in colorectal cancer. Cancer. 1993;71(8):2454-2460.

34. Koenders PG, Peters WH, Wobbes T, Beex LV, Nagengast FM, BenraadTJ. Epidermal growth factor receptor levels are lower in carcinomatous than in normal colorectal tissue. Br J Cancer. 1992;65(2):189-192.

35. Steele RJ, Kelly P, Ellul B, Eremin O. Immunohistochemical detection of epidermal growth factor receptors on human colonic carcinomas. $\mathrm{Br}$ J Cancer. 1990;61(2):325-326.

36. Koretz K, Schlag P, Möller P. Expression of epidermal growth factor receptor in normal colorectal mucosa, adenoma, and carcinoma. Virchows Arch A Pathol Anat Histopathol. 1990;416(4): 343-349.

37. Moorghen M, Ince P, Finney KJ, Watson AJ, Harris AL. Epidermal growth factor receptors in colorectal carcinoma. Anticancer Res. 1990;10(3):605-611. 
38. Karameris A, Kanavaros P, Aninos D, et al. Expression of epidermal growth factor (EGF) and epidermal growth factor receptor (EGFR) in gastric and colorectal carcinomas. An immunohistological study of 63 cases. Pathol Res Pract. 1993;189(2):133-137.

39. Steele RJ, Kelly P, Ellul B, Eremin O. Epidermal growth factor receptor expression in colorectal cancer. Br J Surg. 1990;77(12): 1352-1354.

40. Atkins D, Rieffen KA, Tegtmeier CL, Winther H, Bonato MS, Störkel $\mathrm{S}$. Immunohistochemical detection of EGFR in paraffin-embedded tumor tissues: variation in staining intensity due to choice of fixative and storage time of tissue sections. J Histochem Cytochem. 2004;52(7):893-901.
41. Beer MW, Ung C, Bacus SS, et al. Heterogeneity of epidermal growth factor receptor (EGFR) expression and variation in immunohistochemistry $(\mathrm{ICH})$ testing may affect access to EGFR targeted therapy in patients with advanced colorectal cancer (CRC). J Clin Oncol (ASCO Meeting Abstracts). 2006;24(Suppl 18):S10104. Abstract.

42. Scartozzi M, Bearzi I, Berardi R, Mandolesi A, Fabris G, Cascinu S. Epidermal growth factor receptor (EGFR) status in primary colorectal tumors does not correlate with EGFR expression in related metastatic sites: implications for treatment with EGFR-targeted monoclonal antibodies. J Clin Oncol. 2004;22(23):4720-4728.

\section{Publish your work in this journal}

OncoTargets and Therapy is an international, peer-reviewed, open access journal focusing on the pathological basis of all cancers, potential targets for therapy and treatment protocols employed to improve the management of cancer patients. The journal also focuses on the impact of management programs and new therapeutic agents and protocols on

\section{Dovepress}

patient perspectives such as quality of life, adherence and satisfaction The manuscript management system is completely online and includes a very quick and fair peer-review system, which is all easy to use. Visit http://www.dovepress.com/testimonials.php to read real quotes from published authors.

\footnotetext{
Submit your manuscript here: http://www.dovepress.com/oncotargets-and-therapy-journal
} 